\title{
Analysis and Detection of Antigen - Antibody Interactions using CMOS Image Sensor
}

\author{
Dr.E.N.Ganesh
}

\author{
VISTAS, VELS University, School of Engineering, Pallavaram, Chennai Tamilnadu, India \\ *Correspondence: enganesh50@gmail.com
}

\begin{abstract}
Different types of immunoassay methods commonly used for antigen antibody reactions. The Presented work focused on invitro diagnostic method based on the biological sensor. The competence of a complementary metal-oxide semiconductor (CMOS) using an indium nanoparticle (InNP) substrate for the high sensitivity diagnosis of antigen/antibody interactions at low concentrations under normal light. This study supported with the help of metal surface, normally metal surface affinity to the biological molecules. The research report says metals like Ta, Ni Au, In Si monolayer surfaces increase protein adsorption on their surface also it can bind with their specific antibody The experimental results show the valuable impact of the CMOS image sensor and InN P substrates for the detection of antigen/antibody interactions. Occasional shaking method also gives the sensitive results.
\end{abstract}

Keywords: CMOS image sensor, Indium Nanoparticle, Troponin and Protein

\section{Introduction}

Immunoassay is molecular recognition of the antigens and antibodies, this biomolecues form a strong and stable binding with their specific receptor sites. Different types of immunoassay methods commonly used for antigen antibody reactions such as radio immunoassay (RIA), Enzyme linked immunosorbent assay (ELISA), and chemiluminescense immunoassay, some expensive instruments and devices such as surface Plasmon Resonance (SPR), microarray are used in the medical and laboratory analysis for antigen antibody diagnosis. Past few years sensing based biological analysis showing potential output by simple and less expensive, which are assembled by semi-conductors. The Presented work focused on invitro diagnostic method based on the biological sensor.

\section{Literature Review}

The competence of a complementary metal-oxide semiconductor (CMOS) using an indium nanoparticle (InNP) substrate for the high sensitivity diagnosis of antigen/antibody interactions at low concentrations under normal light. This study supported with the help of metal surface, normally metal surface affinity to the biological molecules. The research report says metals like $\mathrm{Ta}, \mathrm{Ni} \mathrm{Au}, \mathrm{In} \mathrm{Si}$ monolayer surfaces increase protein adsorption on their surface also it can bind with their specific antibody ${ }^{[1,2]}$. Metal NPs coated with antigen/antibody layers act as a dielectric layer on the conducting sphere, which enhances the number of photons hitting the sensor surface through a light scattering effect ${ }^{[3]}$. Photon number is observed by the CMOS sensor and it converted as digital form with help of analog digital converter (ADC). This Photon number is directly proportional to the digital number observed with the CMOS sensor for detecting antigen/antibody interactions. In this study another methods has followed to simplify the steps, that is occasional shaking method, also it is easy to carry out during invitro analysis and medical diagnosis, if this technology incorporated with medical diagnosis devices and smart phones. To this study antigen antibody interactions were carried out for cardio vascular disease. The cardio vascular disease marker Troponin I and their specific antibodies were used for this study.

\section{Experimental}

\section{Preparation of InNPs substrate}

For an experiment, InNP layer has been made on thin cover glass slides by vacuum deposition principle using thermal evaporation system ${ }^{[4]}$. To this study 5 different thickness substrates were made (Thickness ranges $10 \mathrm{~nm}, 20 \mathrm{~nm}, 30 \mathrm{~nm}$, $40 \mathrm{~nm}$ and $50 \mathrm{~nm}$ ). $25 \mathrm{InNp}$ slides were used for this study (5 slides for each thickness for method I). For occasional shaking method 5 InNP substrates needed to carry out the experiment. All the substrates were washed with deionized water and dried with compressed air, before start our 
experiments. All substrates were analyzed by expose on the CMOS image sensor to measure the photon number.

\section{Antigen, antibody preparation}

The Troponin I diluted with $0.85 \%$ of $\mathrm{NaCl}$ and $1 \% \mathrm{BSA}$ solution to make final concentrations is $20 \mu \mathrm{g} / \mathrm{ml}$. This antigen protein is used for two methods method I (Indirect ELISA relative method) and occasional shaking method (related to sandwich ELISA type). 20 washed InNP substrates were washed and dried with compressed air, and these substrates were used for method I. Then small amount of Troponin I antigen added on the substrates. All the slides were kept on shaker for 1 hour incubation. All the substrates were washed with deionized water after 1 hour incubation and dried with compressed air. Again all the substrates were analyzed by the CMOS sensor, to analyze number of photons blocked by the antigen layer. Specific primary antibody diluted in $1 \%$ bovine serum albumin (BSA) for different concentration. The final concentration of primary antibody solution ranges $100 \mu \mathrm{g}$, $100 \mathrm{ng} / \mathrm{ml}, 100 \mathrm{pg} / \mathrm{ml}$ and $100 \mathrm{fg} / \mathrm{ml}$. Then add the primary antibody solution on the antigen coated substrates for different concentrations, all the primary antibody added substrates kept on the shaker for 1 hour incubation under room temperature. All the substrates were washed with deionized water after the incubation period, and then dried the substrates with compressed air followed by kept on the sensor surface to analyzed photon number. A selective secondary antibody was diluted with $1 \%$ BSA to a final concentration of $1 \mu \mathrm{g} / \mathrm{ml}$, add the secondary antibody on the primary antibody and antigen complex layer and leave it for 2 hour incubation under room temperature at shaker. Then the substrates were washed with deionized water to remove the unbound proteins, now the all the unbound proteins removed from the substrates and dried the substrates with compressed air. Again all the substrates kept on CMOS sensor for photon analysis. The 5 InNP substrates (1 substrate in each thickness) were processed for negative control studies. Similarly as the previous protocol by incubation with $\mathrm{Ag} / \mathrm{BSA} /$ secondary $\mathrm{Ab}$ solution, and then analyzed for the photon number and this 5 slides considered as a negative control to find out the non specific adsorption.

For occasional method capture antibody and detection antibody used instead of primary and secondary antibodies. For this method, capture antibody diluted with $1 \%$ BSA solution for different concentration $(100 \mu \mathrm{g} / \mathrm{ml}, 100 \mathrm{ng} / \mathrm{ml}$, $100 \mathrm{pg} / \mathrm{ml}$, and $100 \mathrm{fg} / \mathrm{ml}$ ) and stored cool condition. Add the different concentration of capture antibody added on the InNP substrates, and kept for 1 hour incubation. During the incubation all InNP substrates were kept it on the shaker and spin at every $30 \mathrm{mins}$ at $60 \mathrm{rpm}$ for $10 \mathrm{mins}$. This step supposed to follow after each addition of proteins. After $1 \mathrm{hr}$ incubation substrates were washed with deionized water and kept on the sensor surface to analyzes the photon count, that photons blocked by the capture antibody layer. Then add the
Troponin I antigen on the capture antibody added substrates followed by kept the substrates for incubation as metioned at first step. After incubation wash the slides with deionized water then dried with compressed air and kept on the sensor surface. Now the antigen antibody complex blocked the photons count were analyzed by the CMOS sensor. Then add the detection $\mathrm{Ab}$ on the Ag/capture $\mathrm{Ab}$ added substrate and incubate for 2 hours. Then washed with deionized water to remove all unbound proteins, followed by kept on the sensor surface. Negative control has prepared. For this, add the capture antibody on the $10 \mathrm{~nm}$ InNP substrate and follow the previous protocol and incubation process, which was followed for occasional shaking method, but BSA solution added instead of Antigen. Then detection Ab added on the Capture Ab/Ag added substrate. The negative control substrates also analyzed by the CMOS sensor after each addition of proteins.

\section{Results and Discussion}

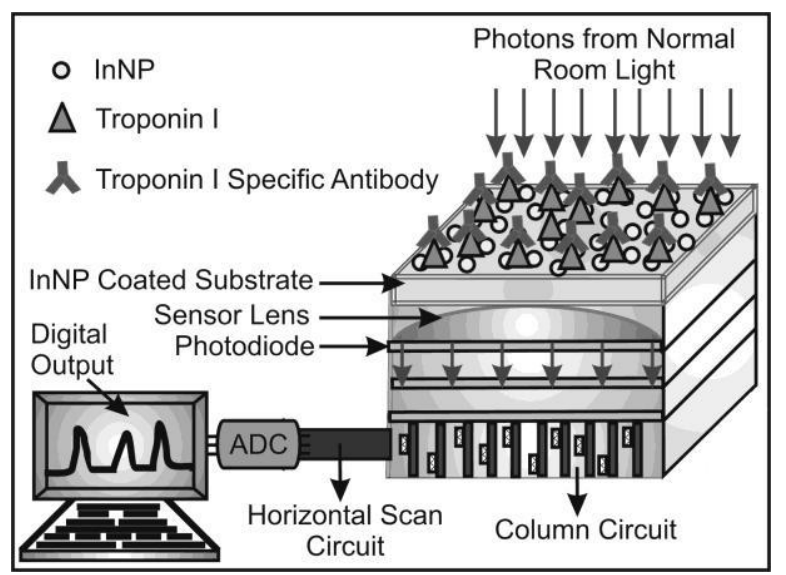

Fig 1: Schematic representation of the CMOS image sensor based antigen- antibody interactions

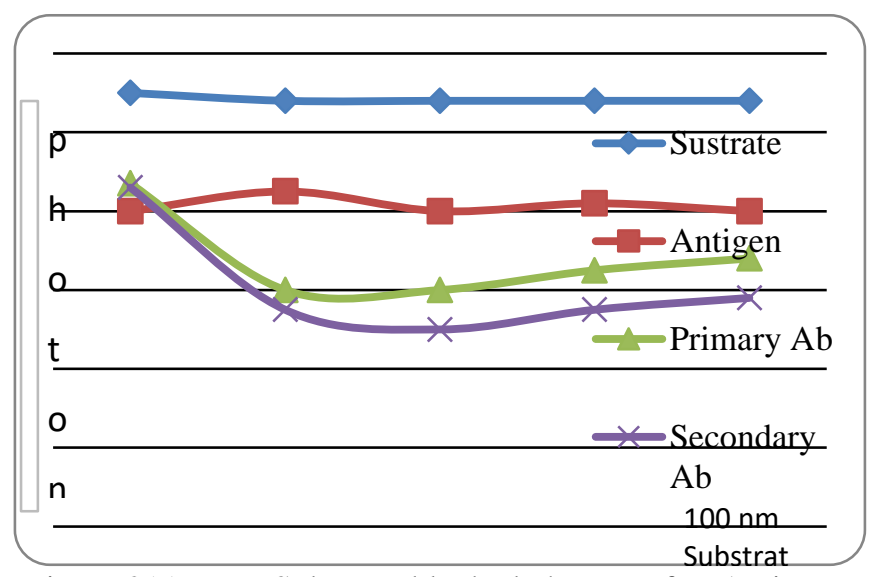

Figure 2(a) InNP Substrate blocked photons after Antigen Binding 


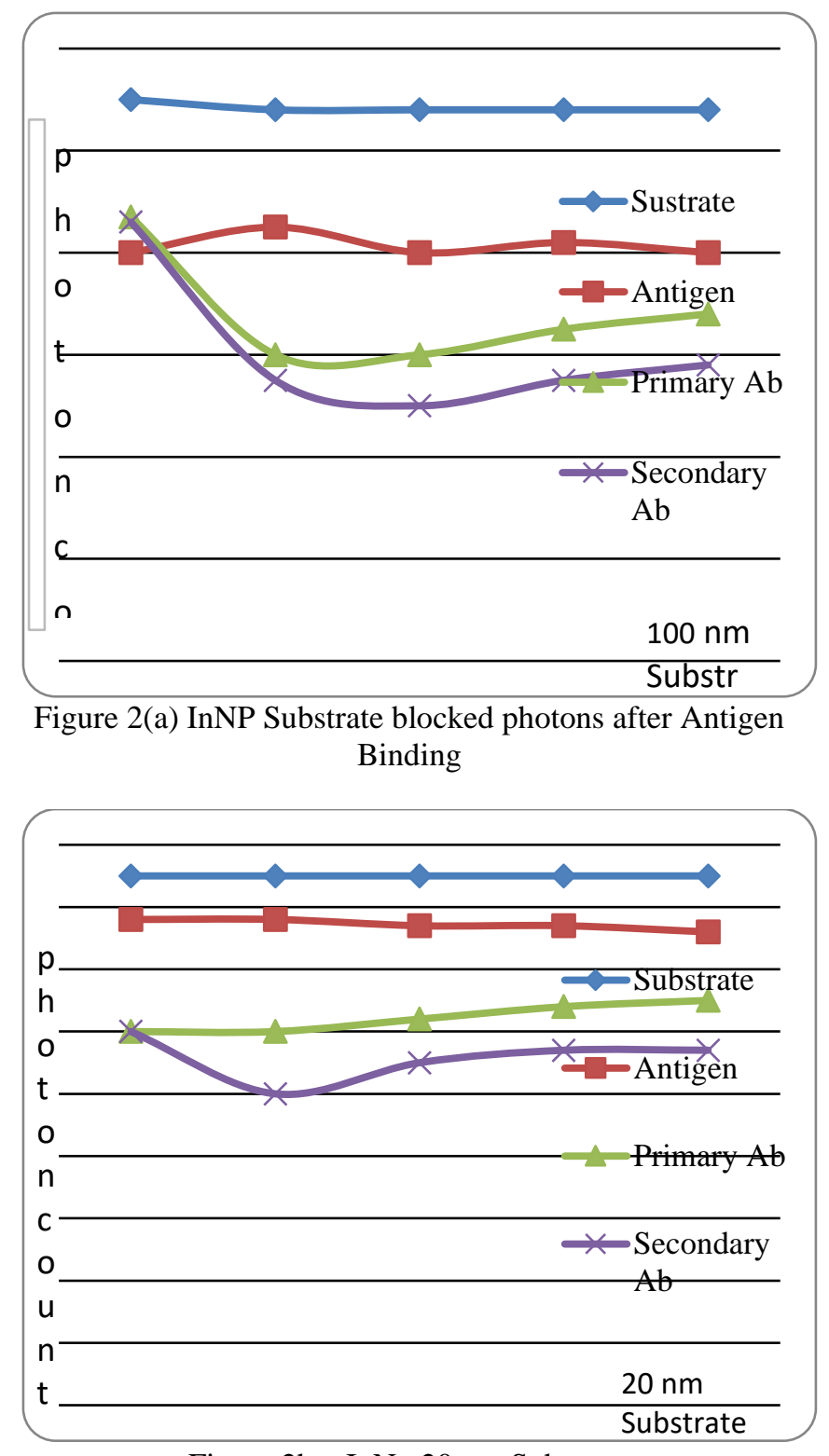

Figure $2 b-\operatorname{InNp} 20 \mathrm{~nm}$ Substrate

Experimental results represented as the number of photons analyzed by the CMOS image sensor for the consequent layers of antigen, Primary antibody, and secondary antibody of InNP substrates and analyzed the interaction for occasional shaking method. Generally, CMOS image sensor contains a photodiode; this photodiode detects the light and converts as electrical energy by the photoelectric concept ${ }^{[3]}$. Here we have attached an analog digital converter to convert the electrical energy into digital form and this concept has described in figure 1.

Figure 2 (a-e) demonstrates the results for method I and this photon number decrease in the antigen added substrate individually according to the substrate concentration. Also the photon count increases based on primary antibody concentrations.

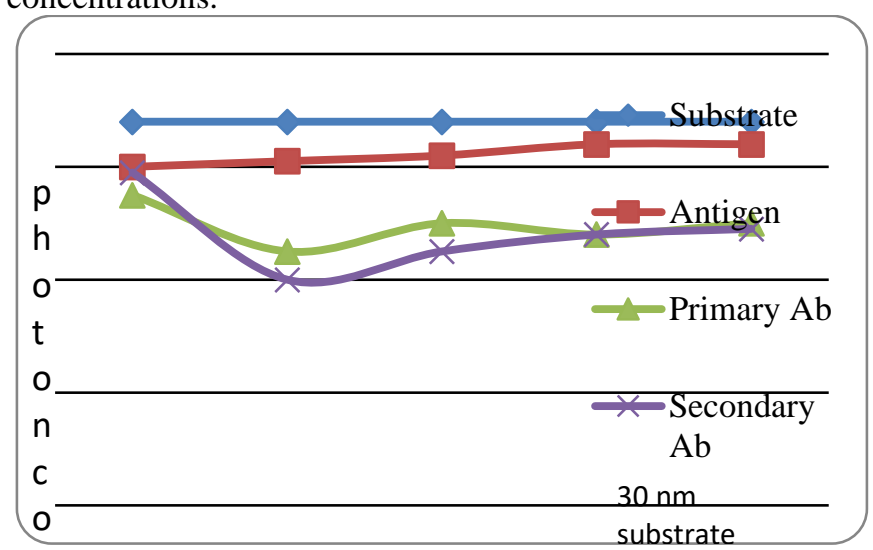

Figure $2 \mathrm{c}-\mathrm{InNp} 30 \mathrm{n} \mathrm{m}$ Substrate

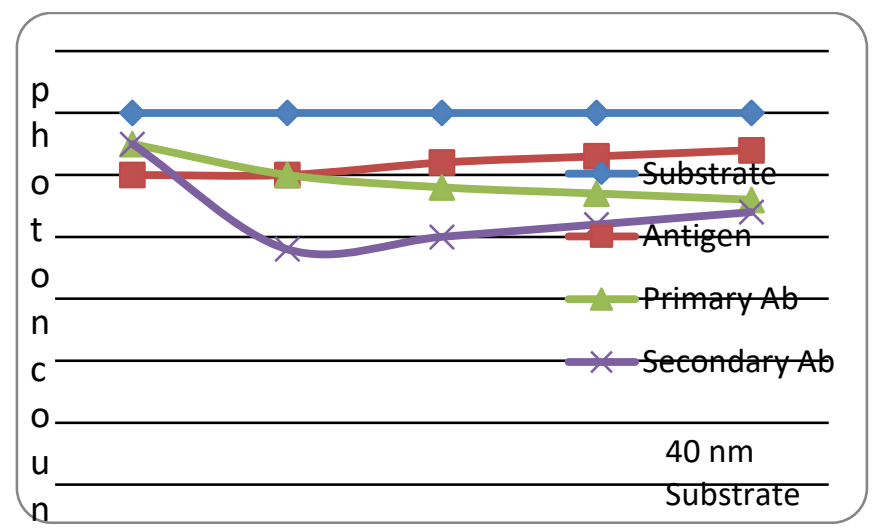

Figure $2 \mathrm{~d}$ - InNp 40nm Substrate

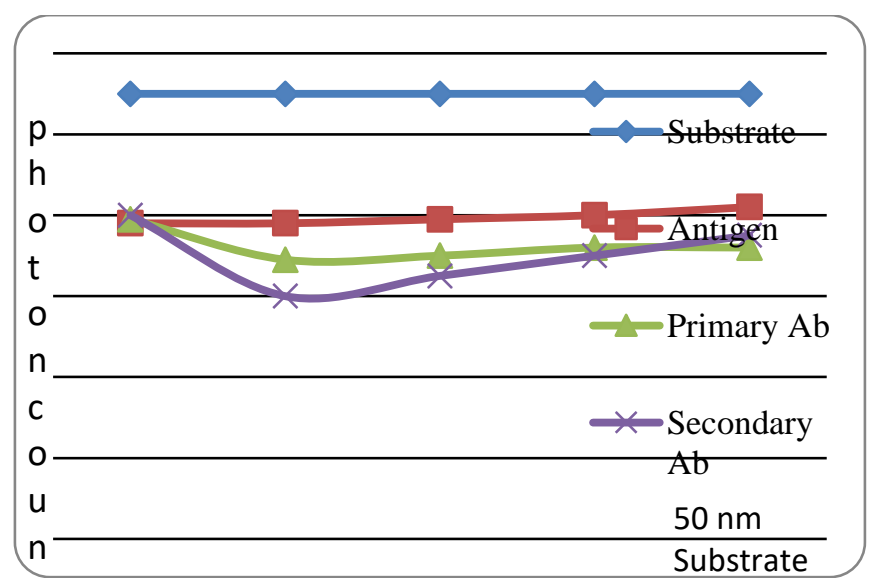

Figure $2 \mathrm{e}-\mathrm{InNp} 50 \mathrm{~nm}$ Substrate

Based on this results we can concluded that the all the substrates adsorb the protein, the photon counts also decreases in each addition of proteins on the InNp substrates. But 10nm substrates shows the high affinity and high sensitivity compare with other slides, as per the results 
Troponin I protein is suitable for $10 \mathrm{~nm}$ substrates that others. Moreover, adsorption capacity has decreased when the substrate thickness increases for this protein. Some alloy surface increases the adsorption on their surface for some proteins ${ }^{[5]}$. By the way, further study under process to improve the affinity on the alloy substrate for all thicknesses of InNP and carry out some other proteins interactions. The negative control sample prevents the non specific adsorption,since, the photon count has decreased once added the Ag on the negative control substrates followed by there is no changes occur after addition of BSA and secondary antibody, Now it proved non specific reaction has prevented by this study. Aim of the occasional shaking method is simplify the process and easy detection. It is reducing the multiple steps. Since, the conventional ELSIA method takes long time to complete the whole process. But occasional shaking method consuming less time and with out any complex. Anyone can use this procedure and detect the results without any difficulties by using the CMOS sensor. Moreover, already specific capture antibody attached substrates is very easy to carry out the remaining steps, only addition of antigen and detection Ab steps are required. It will be more acceptable technique, if this concept incorporates with medical diagnosis devices. Figure 3 demonstrate the results for occasional shaking method and it showed that the photon count decreased after addition of capture antibody on the InNP substrate. Also the photon count has increased gradually, when the capture antibody concentration decreased ${ }^{[6]}$.

This occasional shaking method has done only $10 \mathrm{~nm}$ substrate. Besides, this is the basic step to reach the next level. Generally the conducting metal like indium involved in the scattering of electromagnetic radiation, when the substrate coated with thin dielectric layer. In this study dielectric layer means antigen antibody adsorption on the InNp coated substrate ${ }^{[3,6]}$. That is the reason scattering by the antigen antibody layer on the InNP substrate. It leads to help the antigen antibody interaction very tiny amount like $\mathrm{fg} / \mathrm{ml}$ concentration. Aim of this both type of antigen antibody interactions is very effective method for invitro analysis. From these results first method like Ag/primary $\mathrm{Ab} /$ secondary $\mathrm{Ab}$ interaction gives more sensitive that occasional shaking method, but that method I takes long time to complete process compared with occasional shaking method. But it gave sensitive results due to the continuous shaking. Continuous shaking gives more affinity to the proteins to attach on the InNP surface. Occasional shaking method gives positive and considerable results only, but less sensitive compare with method

\section{Conclusion}

In NP substrate plays an important role in photon analysis. The experimental results show the valuable impact of the CMOS image sensor and InNP substrates for the detection of antigen/antibody interactions. Occasional shaking method also gives the sensitive results. The detailed study under progress to find out the mechanism of protein attached on InNP surfaces and their interactions. Moreover, to carryout the antigen antibody interactions on the alloy surfaces and their principles involved. Proper size of the protein improved scattering with their specific thickness of the InNP substrates.

\section{References}

[1]. E. Stern, JF Klemic, DA Routenberg, PN Wyrembak DB Turner-Evans, AD Hamilton, DA LaVan, TM Fahmy, MA (2007). Reed Label Free Immuno detection with CMOS Compatible Semiconductor Nanowires. Nature 4(45), 519-522.

[2]. V.Stadler, M .Beyer, K. Konig, A.Nesterov, G.Thoralba, V.Lindenstruth, M. Hausmann, F.R. Bischoff, F. Breitling,(2007) Multifunctional CMOS microchip coatings for protein and peptide arrays. Journal of proteome Research (6), $3197-$ 3202.

[3]. I. Giaever etal.(1973) The Antibody-Antigen Reaction: A Visual Observation. The Journal of Immunology 110,1424-1426.

[4]. JA Lodriguss J A, digital book titled " A guide to Astrophotography" http://www.astropix.com/GADC/SAMPLE3/ SAMPLE3.H

[5]. I. Giaever, RJ Laffin (1974) Visual Detection of Hepatitis B Antigen (Immunoassay/protein adsorption. Proceeding of National Academic Sciences USA 71,4533-35.

[6]. HJ Scharfman,(1954) Scattering from dielectric coated spheres in the region of the first resonance. Journal of Applied Physics 25, 1350-52. 